\title{
Analysis of the Status Quo of Changsha's Regional Financial Center
} Jiacen Chen, Hua Deng ${ }^{*}$

College of Mathematics and Finance, Hunan University of Humanities, Science and Technology, Yucai Rd, Louxing District, Loudi, Hunan, China

DOI: $10.36347 /$ sipms.2020.v07i06.002

| Received: 17.06.2020 | Accepted: 25.06.2020 | Published: 30.06.2020

*Corresponding author: Hua Deng

Abstract

Review Article

This paper constructs an index system of financial agglomeration, further evaluating and analyzing the agglomeration level of the financial industry in Changsha. On this basis, the following conclusions are drawn: First, the location entropy index of Changsha's financial industry location index is 0.19 in 2016, which is lower than that of 2015. Since 2016, the financial industry in Changsha has been showing a trend of sustained low-speed growth. The growth rate of the financial industry has dropped significantly. Secondly, the grey correlation degree of each industry is calculated through the grey relational analysis model. As a high-level tertiary industry, the financial industry has a lower grey correlation degree with the tertiary industry's gross regional product than that of the lower level transportation and postal industry, as well as wholesale and retail trade. This paper applies location entropy index model and grey relational analysis model to integrate the advantages of similarity coefficient and location entropy, thereby putting forward suggestions for the construction of Changsha regional financial center.

Keywords: Regional financial center; location entropy index; grey relational analysis.

Copyright @ 2020: This is an open-access article distributed under the terms of the Creative Commons Attribution license which permits unrestricted use, distribution, and reproduction in any medium for non-commercial use (NonCommercial, or CC-BY-NC) provided the original author and source are credited.

\section{INTRODUCTION}

In contemporary China, regional economic development has become increasingly fierce. Finance, as a key factor in contemporary economic growth, plays an important role in promoting both regional economic growth and social development. Financial industry is not only an important part of modern service industry, but also an important support for the development of modern service industry. Hunan, as Changsha's financial ecological zone, is also committed to vigorously developing a consensus on the financial industry. In the "Hunan Financial Development Plan" issued in 13th Five-Year Plan, the financial industry was proposed as an important pillar industry in the province.

Ren Shuxia used the panel data model [1] to empirically analyze the relationship between China's urban financial industrial agglomeration and urban economic growth, and drew the conclusion that the city is the central point of regional economic developmment. The development of financial aggregation or financial centers can enhance the competitiveness of cities, while also facing the negative impact such as the occurrence and spread of risks. Xie Min [2] utilized spatial Gini coefficient and location entropy to calculate the agglomeration degree of the tertiary industry in Zhejiang province from 2003 to
2012, and the reason for agglomeration was explored through spatial error model and spatial lag model. However, the correlation between industries in the development of the tertiary industry was not taken into account. Yin Zheng [3] used the industrial specialization index and location entropy grey correlation analysis method to measure the situation and evolution of the industrial division of labor in various cities as Beijing, Tianjin and Hebei provinces in 2004, 2008 and 2012, respectively. The industrial structure of each city was evaluated as well.

Based on the above background, the historical data of GDP, wholesale and retail trade, transportation and postal industry, accommodation and catering industry, financial industry and real estate in Hunan province and Changsha city during the period of 20142018 , the index system of financial agglomeration in Changsha is constructed. In the empirical analysis, we apply Execl and Matlab to analyze the current situation of Changsha's regional financial center through location entropy index and grey relational analysis. On the whole, the paper can provide further scientific reference for Changsha to build a regional financial center. 


\section{The index system of financial agglomeration in Changsha}

In this paper, the index system of financial agglomeration degree is established, and the specific structure of the tertiary industry in Changsha is analyzed by the location entropy index model. However, the similarity degree of the five main industries in the tertiary industry cannot be quantitatively measured. Thus, the grey relational analysis model is established so as to solve the problem, which combines the advantages of similarity degree and location entropy, so that more information in the industrial structure can be excavated more effectively.

\section{The Location Entropy Index}

The location entropy index $\left(L Q_{i j}\right)$ is also known as the degree of local specialization, which is a significant indicator in measuring the spatial distribution of elements in a certain area, reflecting the specialization degree of an industry, as well as the status and role of a certain region in the high-level region. It plays an important role in the study of industrial structure. The higher the value of $L Q_{i j}$, the higher the level of industrial agglomeration and the higher degree of specialization in the area. If the index value is greater than 1 , it shows that the agglomeration level of the industry in this area is quite high, and the regional economy in this area has an advantage in the whole province.

The location entropy formula is as follows:

$$
L Q_{i j}=\frac{\frac{q_{i j}}{q_{j}}}{\frac{q_{i}}{q}}
$$

Among which, $L Q_{\mathrm{ij}}$ It is the location entropy of $i$ industry in $j$ Province in the whole province; $q_{i j}$ is related indicator for I industry in $\mathrm{J}$ area; $q_{j}$ refers to relevant indicators for all industries in $\mathrm{J}$ area; $q_{i}$ refers to the relevant index of $I$ industry in the whole province; $q$ is related indicator for all industries in the province.

\section{Grey Relational Analysis}

Grey relational analysis is a method to measure the degree of the correlation among factors, whose basic idea is to determine the degree of synchronous change between the reference data column and the geometric similarity of several comparative data columns, which reflects the degree of the correlation between curves.

This method is usually used to analyze the degree of the influence of various factors on the result, and can also be used to solve time-varying comprehensive evaluation problems. The core of the problem is to establish the time sequence of the parent sequences according to certain rules. If the trend of the change of the parent sequence and its subsequence is consistent, the degree of synchronous change is relatively high.

\section{The steps of grey relational analysis are as follows}

1) Determine the sequence of analysis

A series of reference sequences reflecting the characteristics of a system and a series of comparisons that affect the behavior of the system are determined. A series of data reflecting the characteristics of a system is called a reference sequence. A series of data that affects the behavior of a system is called a comparison sequence.

2) Dimensionless processing of reference sequence and comparative sequence.

Because of the different physical meaning of each factor in the system, it is not easy to acquire the correct conclusions in comparison. Therefore, in the grey correlation analysis, the data must be dimensionless. There are two methods to deal with the data: initial value processing and averaging processing.

(3) Calculate the correlation coefficient $\delta_{i}(k)$

$$
\begin{aligned}
& \delta_{i}(k)=\frac{\min _{i} \min _{k}\left|y(k)-x_{i}(k)\right|+\rho \max _{i} \max _{k}\left|y(k)-x_{i}(k)\right|}{\left|y(k)-x_{i}(k)\right|+\rho \max \max _{k} \mid y(k)-x_{i}(k||} \\
& \triangle_{i}(k)=\left|y(k)-x_{i}(k)\right| \\
& \delta_{i}(k)=\frac{\min _{i} \min _{k} \Delta_{i}^{(k)+\rho} \max _{i} \max _{k} \Delta_{i}(k)}{\Delta_{i}(k)+\rho \max \max _{k} \Delta_{i}^{(k)}}
\end{aligned}
$$

Among which, $\rho \in(0, \infty)$, The smaller the resolution is, the larger the resolution will be. The interval of general $\rho$ value is $(0,1)$, and the specific value depends on the situation. When $\rho$ is less than 0.5463 , the resolution is regarded as the best, which is usually 0.5 . 
(4) Calculate the correlation degree $r_{\mathrm{i}}$

Since the correlation coefficient is the correlation degree between the comparison sequence and the reference sequence at any time (i.e. the points in the curve), it has more than one value, and the information is too dispersed to facilitate the overall comparison. Therefore, it is necessary to gather the correlation coefficient of the points at each time (i.e. the points in the curve) into one value, that is, the average value. As the quantity represents the correlation degree between the comparison sequence and the reference sequence, the correlation degree $r_{\mathrm{i}}$ is calculated as follows:

$r_{i}=\frac{1}{n} \sum_{k=1}^{n} \delta_{i}(k), k=1,2, \ldots, n$

\section{The degree ranking of association}

The degree of association is sorted according to size. $r_{1}<r_{2}$ reference series $y$ is more similar than comparison series $x_{2}$. Figure out $x_{i}(k)$ sequence and $y(k)$ after calculating the correlation coefficient of the series, the average values of all kinds of correlation coefficients are calculated. $y(k)$ and $x_{i}(k)$ are called the degree of correlation.

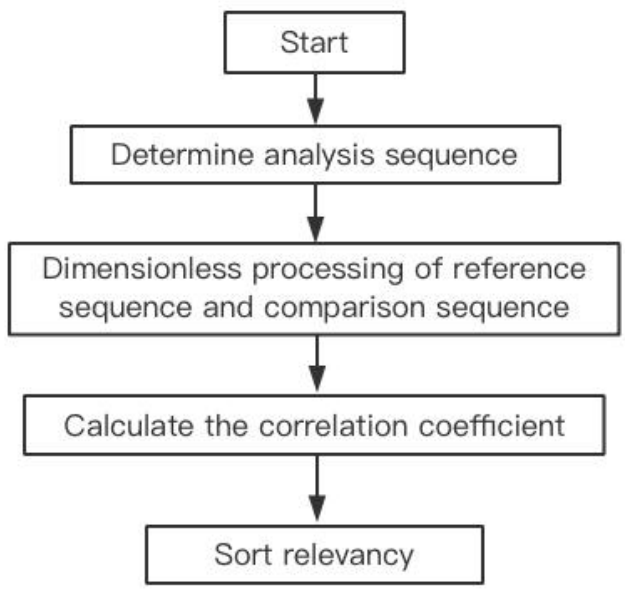

Chart-1: Flow chart of grey relational analysis model

\section{EMPIRICAL ANALYSIS}

In this section, based on the relevant data of the regional GDP of wholesale and retail trade, transportation and postal industry, accommodation and catering industry, financial industry and real estate, Matlab is used to calculate the location entropy index of the above industries in Changsha, and the location entropy index is used to measure the agglomeration degree of financial industry in Changsha City in 2014. However, the location entropy index model cannot quantitatively measure the similarity of the industrial structure of the two regions. Therefore, the grey relational analysis model is applied to integrate the advantages of similarity coefficient and location entropy, so as to excavate more information of Changsha's industrial structure more effectively. This paper analyzes the present situation and challenges of the construction of regional financial centers in Changsha. The data comes from the five major industries from 2014 to 2018 of the Hunan Statistical Yearbook and Changsha Statistical Yearbook, the total value of the tertiary industries in Hunan and Changsha, and the five major industries in the wholesale and retail trade, transportation, storage and postal industry, accommodation and catering industry, financial and real estate in the tertiary industry.

\section{Location entropy index model of financial agglomeration degree in Changsha}

In this model, the financial industry is taken as an example. $L Q_{\mathrm{ij}}$ is the location entropy of the GDP of Changsha's financial industry in the whole province. $q_{i j}$ refers to the GDP of Changsha's financial industry; $q_{j}$ is the total GDP of all industries in Changsha; $q_{j}$ refers to the GDP of the financial industry in the whole province. $q$ refers to the GDP of all industries in the province. The location entropy index model is used to calculate the location entropy index of the major industrial regions of the tertiary industry in Changsha in the period of 2014-2018.

Table-1: Location entropy index of GDP in tertiary industries of Changsha from 2014 to 2018

\begin{tabular}{|l|l|l|l|l|l|}
\hline & $\begin{array}{l}\text { Wholesale and } \\
\text { retail trade }\end{array}$ & $\begin{array}{l}\text { Transportation and post } \\
\text { industry }\end{array}$ & $\begin{array}{l}\text { Accommodation catering } \\
\text { industry }\end{array}$ & Finance & $\begin{array}{l}\text { Real } \\
\text { estate }\end{array}$ \\
\hline $\mathbf{2 0 1 4}$ & 1.20 & 0.74 & 1.11 & 1.66 & 0.91 \\
\hline $\mathbf{2 0 1 5}$ & 1.15 & 0.74 & 1.10 & 1.67 & 0.96 \\
\hline $\mathbf{2 0 1 6}$ & 1.16 & 0.75 & 1.07 & 1.48 & 1.05 \\
\hline $\mathbf{2 0 1 7}$ & 1.16 & 0.73 & 1.04 & 1.47 & 0.99 \\
\hline $\mathbf{2 0 1 8}$ & 1.25 & 0.80 & 1.12 & 1.60 & 1.31 \\
\hline
\end{tabular}

According to the data in Table-1, from 2014 to 2015, the total entropy index of GDP in Changsha financial district showed an upward trend. In 2015, the location entropy index reached 1.67. From 2016 to 2018, the location entropy index decreased, but showed a relatively stable upward trend. The data showed that the location entropy index of the financial industry was always higher than the other four industries, which means that the scale of Changsha's financial industry has a certain advantage compared with other industries. 
According to the above data, Changsha as a provincial capital in Hunan province, has always maintained a location entropy index of more than 1 throughout the whole province. The development of the financial industry is at a specialized level in Hunan province. Compared with other cities in Hunan Province, Changsha has an economic foundation, abundant resources and the importance of local governments in developing regional financial centers in recent years.
Grey relational analysis model of the degree of financial agglomeration in Changsha

This model takes the GDP of the tertiary industry in Changsha from 2014 to 2018 as a reference list. The data of gross output of wholesale and retail industry, transportation and postal industry, accommodation and catering industry, financial industry and real estate industry are all listed as comparison series. By means of averaging, calculating absolute difference and correlation coefficient, the grey correlation degree of each industry is calculated, as shown in Figure-1.

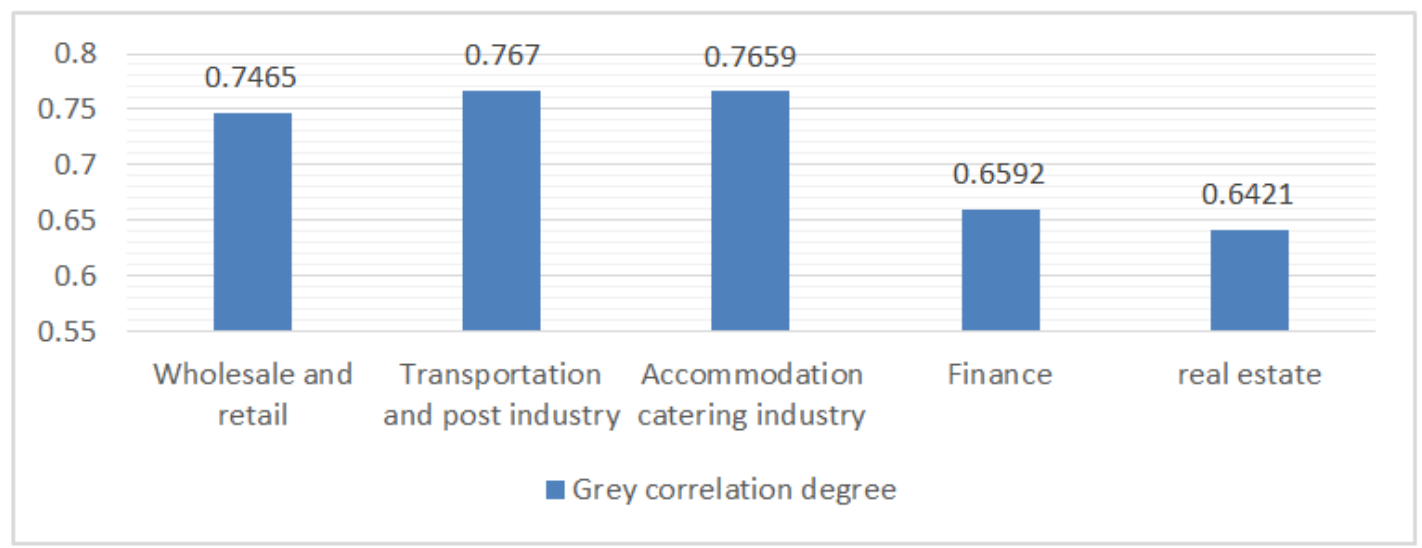

Fig-1: Grey correlation degree of gross industrial area in Changsha

The order can be eliminated by the correlation degree as $r_{2}>r_{3}>r_{1}>r_{4}>r_{5}$. It can be seen that the industry with the largest correlation in the tertiary industry is transportation and postal industry. Compared with other industries, the financial industry, as a high-level tertiary industry, has little effect on promoting GDP growth, and there is great space for future development.

\section{Challenges and suggestions for Changsha's regional financial centers Challenges}

Although Changsha's financial strength has been steadily improved, its economic indicators have increased rapidly, and the financial industry has been firmly established, while the total amount is not large, the proportion is low, and the strength is not strong. The status quo of Changsha's financial agglomeration index system is still very clear. There are various problems in establishing a regional financial center based on the central and western regions.

The growth rate of the financial industry has dropped significantly. According to the location entropy index data of the GDP of the tertiary industry from 2014 to 2018, the location entropy index of Changsha's financial industry has shown an overall upward trend. However, since 2016, the financial industry in Changsha has been showing a sustained low growth trend. Compared with other service industries, the growth rate of Changsha's financial industry is relatively low, whose growth rate is relatively low as well, and there is a downward trend. The tertiary industry in Changsha still has a low level of development, and the growth of the financial industry is slowing down.

The role of the financial industry is not obvious. According to the grey correlation analysis of the GDP in Changsha, the financial industry as a highlevel tertiary industry has a smaller grey correlation with GDP of the tertiary industry than that of the lowlevel transportation and postal industry as well as wholesale and retail trade. The internal development level of the tertiary industry in Changsha is relatively low. As an important key factor of contemporary economic growth, finance plays an essential role in promoting regional economic growth and social development. The financial industry is not only an important part of modern service industry, but also an important support for the development of modern service industry, which is Changsha's financial ecological zone. We are committed to developing the consensus of the financial industry.

\section{SUGGESTIONS}

Based on the location entropy index and the grey correlation analysis, this paper makes a longitudinal comparison of the financial agglomeration of Changsha from 2014 to 2018, which proves that the development of the financial industry in Changsha is unstoppable. Under favorable policies and plans, 
Changsha's financial industry will have great room for development in the future. Therefore, it is of great practical significance to study the current status of the construction of Changsha's regional financial center. According to the analysis of Changsha's financial agglomeration based on the above index system, the following suggestions are proposed for the construction of Changsha's regional financial center.

\section{1) Efforts should be made to promote the high- quality development of the financial industry}

First, we should enhance both location advantages and external radiation capability of Changsha; strengthen the construction of transportation infrastructure as well as the information network. In addition, it is of great necessity to raise the level of science and technology, and support the construction of the "hardware" location environment for the development of various financial functions. Second, speed up the economic development. We should take the grand goal of creating a national central city and realizing the basic modernization as the guidance focus on innovation and lead the development, further building a strong economy, and constantly enhance Changsha's competitiveness, radiance and attractiveness. Third, we should optimize the institutional environment, continue to improve the financial system, mechanism, policy and legal environment, focus on the development of financial intermediary service institutions, strengthen the precaution and early warning of regional financial risks, and enhance the effectiveness of financial supervision and coordination. Finally, we must optimize the talent team, improve the long-term mechanism, so as to promote the construction of financial talent system, strengthen the introduction of financial talents, and implement the reward plan for high-end talents, thus making Changsha a talent plateau for the financial industry.

\section{2) Give full play to the role of the financial industry in the tertiary industry}

First, increase financial support, actively expand financing channels, accelerate the accumulation of various financial institutions, support the development and growth of enterprises, and increase the introduction of financial and foreign capital as well as the high-quality financial institutions in Changsha. Second, there are three strategic positioning of Beijing Guangzhou, Hu Kun, Chongqing high speed railways in Changsha, and Huanghua Airport is listed as the world's 100 strongest airports. Meanwhile, Changsha is the important node city of "The Belt and Road Initiative", "the first city in a belt" and the central city group of the middle reaches of the Yangtze River, so as to further promote the interaction and cooperation between Changsha and the outside world. We will help Changsha build an open and distinctive financial centre. Third, we should raise the level of financial internationalization, learn from international experience, and accelerate the construction of an open financial service system that is conducive to the upgrading of export products and supporting enterprises to enter the global stage.

In the future, the development of Changsha's financial industry needs to be further enhanced in the level of financial technology, and we should build a qualified environment for technological and financial innovation so as to form a talent gathering and technology financial center throughout the country.

\section{CONCLUSION}

In this paper, the index system of financial agglomeration is constructed. Based on the location entropy index model and the grey relational analysis, the level of the financial industry agglomeration in Changsha is evaluated and analyzed. Based on this, the following conclusions can be drawn as follows. First, the growth rate of the financial industry has dropped significantly. The location entropy has been promoting the high-quality development of the financial industry. The entropy index has decreased by 0.19 compared to 2015. The development of the financial industry presents a downward trend. Secondly, the role of the financial industry is not obvious. As a high-level tertiary industry, the financial industry has a lower grey correlation with the GDP of the tertiary industry compared with the low-level transportation and postal industry as well as wholesale and retail trade, whose role is not obvious either.

Based on the above conclusions, this study puts forward the following suggestions for the establishment of the regional financial center in Changsha. To start with, efforts should be made to promote the high-quality development of the financial industry, in order to strengthen cooperation among modern service industries, to integrate the resources required for the development of the tertiary industry, and to maximize the utilization of resources. Then, we should give full play to the role of the financial industry in promoting the tertiary industry, further to speed up the gathering of various financial institutions. What's more, we should increase the introduction of foreign capital and introduce high-quality financial institutions to Changsha.

\section{ACKNOWLEDGEMENTS}

This research is financially supported by the Undergraduate Innovation and Entrepreneurship Training Program of Hunan University of Humanities, Science and Technology, China (Research on the impact of the construction of financial industry entity service on urban planning based on POI data-Taking Changsha as an example, 2019), the Collegeenterprise Cooperation Curriculum Project for Financial Engineering of Hunan University of Humanities, Science and Technology, China (2017), and the College-enterprise Cooperation Textbook Project for 
Financial Engineering of Hunan University of Humanities, Science and Technology, China (2017). All the persons involved in the research projects are thanked for their help.

\section{REFERENCE}

1. Ren, S. (2011). Research on financial agglomeration and urban economic growth. Beijing University of Posts and Telecommunications.

2. Xie, M., Zhao, H., Zhu, N., \& Xie, G. (2015). Characteristics and causes of spatial agglomeration of third industries in Zhejiang province. Economic geography, 35(9):96-102.

3. Yin, Z., \& Minghua, L. (2015). Study on the change of industrial division between cities in Beijing Tianjin Hebei region. Economic geography, 35(10):110-115.

4. Jin, R., Guo, J., \& Li, F. (2019). The Development Level Comprehensive Evaluation and the Regional Differentiation Characteristics Analysis of Shipbuilding Industry Agglomeration in Chinese Coastal Areas. Journal of Coastal Research, 98(SI), 203-206.

5. Sun, X., Pan, Z., \& Chen, V. (2016). Factors affecting the construction of regional financial centers in Chengdu. Finance and economics, (2): 34-41.

6. Bean, X. L. (2014). Measurement and evaluation of Zhengzhou's Financial Industry Agglomeration -- Also on the construction of the core function area of the new financial agglomeration of Zheng Dong New District. Credit reporting, 32(9): 76-80.

7. Editorial Department of this journal. (2014). "One belt and one area": a new orientation of Hunan's location advantage. New Hunan review, (5):13-17.

8. Zheng, D. (2018). Investigation and analysis of Changsha's construction of regional financial center. Hunan University.

9. Hu, X. (2009). Financial aggregation and the formation of regional financial centers. Financial theory and practice, (10): 62-65.

10. Zhou, H., \& Chen, J. (2009). Comparative study on financial development between Wuhan and five cities in China. Yangtze River forum, (3):38-43.

11. Zhang, J. (2008). Research status of regional financial innovation theory at home and abroad. today, Keyuan, (6): 12.

12. Zhao, X. (2009). Research on the development of financial industry in Changsha central business district (CBD). Hunan Normal University. 